\title{
THE OCEAN SURFACE TOPOGRAPHY CONSTELLATION: THE NEXT 15 YEARS IN SATELLITE ALTIMETRY
}

\author{
Stan Wilson ${ }^{(1)}$, François Parisot ${ }^{(2)}$, Philippe Escudier ${ }^{(3)}$, Jean-Louis Fellous ${ }^{(4)}$, Jérôme Benveniste ${ }^{(5)}$, \\ Hans Bonekamp ${ }^{(2)}$, Mark Drinkwater ${ }^{(6)}$, Lee Fu ${ }^{(7)}$, Gregg Jacobs ${ }^{(8)}$, Mingsen Lin ${ }^{(9)}$, Eric Lindstrom ${ }^{(10)}$, \\ Laury Miller $^{(11)}$, Rashmi Sharma ${ }^{(12)}$, Eric Thouvenot ${ }^{(13)}$
}

(1) NOAA/NESDIS (National Oceanic and Atmospheric Administration/National Environmental Satellite, Data, and Information Service), 1335 East West Highway, Silver Spring, MD 20910, U.S.A., Email: stan.wilson@noaa.gov

(2) EUMETSAT (European Organisation for the Exploitation of Meteorological Satellites), Eumetsat-Allee 1, 64295 Darmstadt, Germany, Email: francois.parisot@eumetsat.int; hans.bonekamp@eumetsat.int

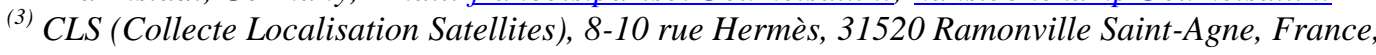
Email: pescudier@cls.fr

(4) JCOMM ((Joint World Meteorological Organisation (WMO)/Intergovernmental Oceanographic Commission (IOC) Technical Commission for Oceanography and Marine Meteorology), clo CNES/COSPAR (Centre national d'Études Spatiales/Committee on Space Research), 2 Place Maurice-Quentin, 75039 Paris Cedex 01, France, Email:_ean-louis.fellous@cosparhq.cnes.fr

${ }^{(5)}$ ESA/ESRIN (European Space Agency/European Space Research Institute), Via Galileo Galilei, Frascati 00044, Italy, Email: jerome.benveniste@esa.int

${ }^{(6)}$ ESA/ESTEC (European Space Agency/European Space Research and Technology Centre), Keplerlaan 1, NL-2201 AZ Noordwijk, The Netherlands, Email: mark.drinkwater@esa.int

(7) JPL (Jet Propulsion Laboratory), MS 300-323, 4800 Oak Grove Drive, Pasadena, CA 91109, U.S.A., Email: llf@jpl.nasa.gov

${ }^{(8)}$ NRL (Naval Research Laboratory, 7320, Stennis Space Center, MS 39529, U.S.A., Email: gregg.jacobs@nrlssc.navy.mil

${ }^{(9)}$ NMEFC/SOA (National Marine Environmental Forecasting Center/State Ocean Administration), 8 Dahuisi Road, Haidian District, Beijing 100081, China, Email: mslin@mail.nsoas.gov.cn

${ }^{(10)}$ NASA HQ (National Oceanic and Atmospheric Administration/Headquarter), MS 3F71, 300 E St. SW, Washington, DC 20546, U.S.A., Email: eric.j.lindstrom@nasa.gov

${ }^{(11)}$ NOAA/NESDIS/LSA (National Oceanic and Atmospheric Administration/National Environmental Satellite, Data, and Information Service/Laboratory for Satellite Altimetry), 1335 East West Highway, Silver Spring,

MD 20910, U.S.A., Email: laury.miller@noaa.gov

${ }^{(12)}$ ISRO/SAC (Indian Space Research Organization/Space Applications Centre), OSD/MOG/RESA (Oceanic Sciences Division/Meteorology and Oceanography Group/Remote Sensing Area, Space

Applications Centre), Ahmedabad 380 015, India, Email: rashmi@sac.isro.gov.in

${ }^{(13)}$ CNES/TSC (Centre National d'Études Spatiales/Signal Theory and Communications), 18 avenue Edouard Belin, 31401 France, Email: eric.thouvenot@cnes.fr

\begin{abstract}
An overriding issue facing the altimetry community today is sustaining the present observational capability. In Europe and the U.S., this involves transitioning altimetry as a research endeavour within the $R \& D$ agencies into a sustained capability within their operational counterparts. Additionally, meeting operational and scientific objectives require multiple orbits. The first is needed to address the role of the oceans in climate, while together they address mesoscale variability or ocean weather. For the longer term, capabilities are needed which feature denser sampling via the development and demonstration of new techniques, one example being wide-swath swath altimetry. Recognizing the need for coordination, the Ocean Surface Topography Virtual Constellation (OST VC) has been established to maximize synergy between the existing and near-term missions; this includes
\end{abstract}

promoting a data policy that enables full and open sharing of data with timely access for all missions, namely, a constellation. Requirements for such a constellation in the near term include maintaining continuity of (1) the low-inclination Jason-class altimeter series to serve as a reference mission, and at the same time (2) altimeters on at least two, preferably three, satellites in complementary high-inclination.

\section{INTRODUCTION}

From the early 1990s learning period to the late 2000s, the community of ocean altimetry data users has grown from a narrow group of selected principal investigators to a broad family of well-trained practitioners, ranging from researchers to operational ocean forecasters. This evolution has been made possible as a result of many advances in satellite technology, algorithm 
development, data processing, communications, and a number of application centres worldwide - the MyOcean consortium in Europe and BlueLink in Australia among others - which have worked at developing integrated, multi-mission products and making them available in near real time for operational use.

Drawing extensively on [1], this Community White Paper has been prepared in conjunction with activities of the OST VC (Ocean Surface Topography Virtual Constellation), a concept initiated by the Committee on Earth Observation Satellites (CEOS). The OST VC serves as a mechanism to harmonize amongst among the altimetry missions of the space agencies of different nations: the National Aeronautics and Space Administration (NASA), the National Oceanic and Atmospheric Administration (NOAA) and the Navy in the U.S.; Centre National d'Études Spatiales (CNES) in France; European Space Agency (ESA) and European Organisation for the Exploitation of Meteorological Satellites (EUMETSAT) in Europe; Indian Space Research Organization (ISRO) in India; and the State Oceanic Administration (SOA) in China. In addition to maximizing synergy between existing and near-term missions, an important goal of the OST VC is to foster the implementation of a sustained, systematic capability to observe the surface topography of the global oceans.

Observations of the surface topography - together with complementary in situ observations collected within the ocean by systems such as Argo - are central to understanding the dynamics of the global oceans, assessing their role in climate, and sustaining a robust operational forecast capability. The report cited above, hence this paper, builds on the recommendations of the Symposium on 15 Years of Progress in Radar Altimetry [2] held in Venice in March 2006, as well as the subsequent Ocean Surface Topography Constellation Strategic Workshop [3], held in Assmannshausen in January 2008. Briefly, these recommendations are to:

- Maintain continuity of high-accuracy Jason altimetry.

- Maintain continuity with altimeters on at least two, preferably three, complementary high-inclination satellites.

- Extend the capability of altimetry to denser observational coverage through wide-swath altimetry.

- Maintain an open data policy including near-real time data for operational purposes.

- Maintain a continuing partnership with the scientific community.

- Maintain a broad collaboration between engineering and science, research and operations, and international partners.

These meetings have helped develop community consensus for the path forward in satellite altimetry. Since the full suite of operational and science objectives for altimetry cannot be met by a single unique mission, the OST VC can serve as a focus for satellite altimetry, maximizing synergy between the missions, as well as improving the efficiency of the overall system.

\section{BRIEF HISTORY}

The initial technical feasibility of satellite altimetry was demonstrated by the $S$-193 multi-purpose microwave instrument on board SkyLab in 1974 and GEOS-3 (Geodynamics Experimental Ocean Satellite) - the first dedicated altimeter mission - the following year; they detected the sea surface height changes from gravitational effects over major trenches. Then during its three-month lifetime in 1978, SEASAT (Sea Satellite) was able to demonstrate that altimetry could observe signatures of oceanic eddies. Launched in 1985, GEOSAT (GEodetic \& Oceanographic SATellite) was used for measuring eddy variability as well as the marine geoid.

Building on this heritage, the European ERS-1 (European Remote Sensing Satellite) was launched in 1991 and ERS-2 followed in 1995; included in the payload for each was an altimeter package; they represented advances in altimetry with their radiometers for the water vapour correction and improved orbit determination. The high-density data set acquired by ERS-1 during its geodetic mission, together with the dense GEOSAT data, once declassified, provided a detailed view of the marine gravity field with a spatial resolution better than $5 \mathrm{~km}$.

As discussed in [1], the accuracy of the U.S./French TOPEX/Poseidon (T/P), launched in 1992, featured even better orbit determination and showed the importance of dual-frequency altimetry for reducing errors due to ionospheric effects. T/P data were also useful for improving the orbits of ERS-1 and -2 through analyses of T/P and ERS crossovers as demonstrated by the AVISO Ssalto/Duacs ${ }^{1}$ project (Archiving, Validation and Interpretation of Satellite Oceanographic data/ Segment Sol multi mission d'Altimétrie, d'Orbitographie et de localisation précise/ Developing Use of Altimetry for Climate Studies).

Anticipating successes realized by ERS-1 and T/P, a strategic planning document, the Purple Book [4], established the concept of a space-based ocean circulation observing system that included (1) a lowinclination mission carrying a high-accuracy altimeter package - a reference mission - on a non-sunsynchronous, repeat orbit for the determination of large-

\footnotetext{
${ }^{1}$ http://www.aviso.oceanobs.com/
} 
scale ocean currents, and (2) complementary higherinclination, sun-synchronous altimeter missions, that extended temporal and spatial sampling to provide information on mesoscale eddies.

This strategy fully came to fruition in the early 2000s. Jason-1, launched in 2001, was conceived by NASA and CNES as a mission to follow $\mathrm{T} / \mathrm{P}$ - maintaining its accuracy, but at a lower cost. The payload for ENVISAT, launched in 2002, included a radar altimeter, the Doris tracking system, and a microwave radiometer. The combination of ENVISAT, Jason-1, T/P - which had been moved to an interleaved orbit with Jason-1, ERS-2, and GFO (GEOSAT Follow-On) allowed highresolution mapping of sea surface height variability such as shown in Fig. 1 and demonstrated the potential capability of multi-satellites altimetry to monitor mesoscale variability and to feed ocean models, paving the way for operational oceanography.

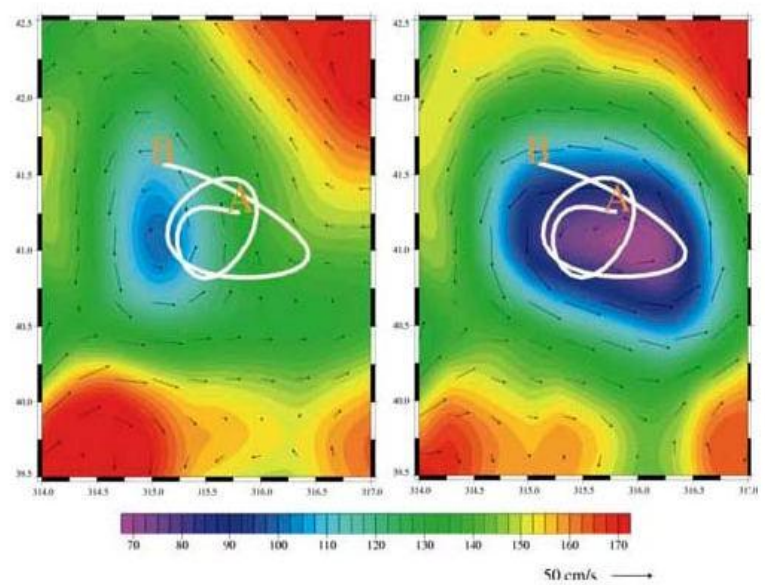

Figure 1. Buoy trajectory (white line from 14-18 May 2003) and merged absolute dynamic topography in the Gulf Stream (for 21 May 2003) using two altimeters (T/P and ERS-2) on the left and four (T/P, ERS-2, Jason $\&$ GFO) on the right [5]. Flying in essentially the same orbit as ERS-2 at that time, ENVISAT was not used, as it would have added redundant information.

The long data record - continuous since 1992 as shown in Fig. 2 - has enabled an analysis of interannual variability, such as the time-evolving spatial extent of the El Niño; has started to resolve decadal variability in the global oceans associated with phenomena such as the North Atlantic Oscillation, Pacific Decadal Oscillation, and Indian Ocean Dipole; and has contributed to the knowledge of the spatial variability of global sea level rise.

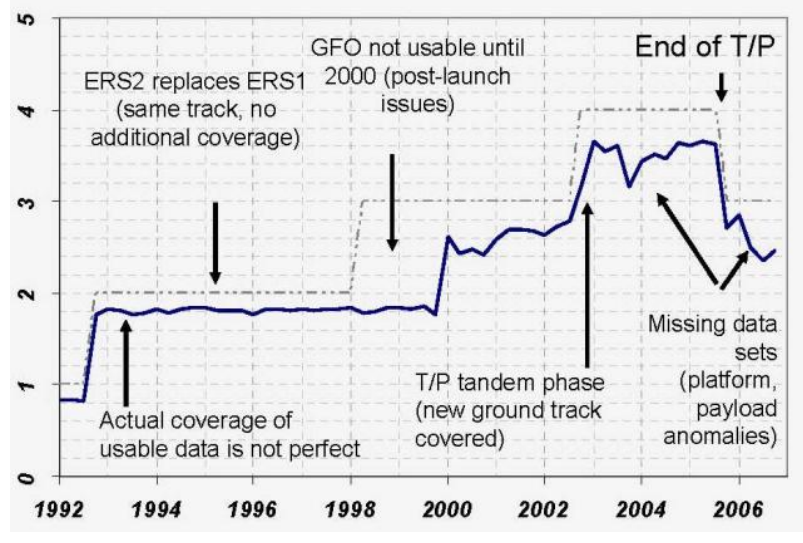

Figure 2. Number of altimeters actually used in operations by Ssalto/Duacs (solid line) compared with the number of altimeters that could have used, assuming ideal coverage and no data lost (dashed line) [from 1].

Additionally, operational centres in a number of different countries had become acquainted with the capability of satellite altimetry and, within their respective countries, expressed interest in the continuation of these series.

This has directly led to the launch of Jason-2 (also known as OSTM, the Ocean Surface Topography Mission) in 2008, a partnership between CNES and NASA that includes EUMETSAT and NOAA, their operational agency counterparts, being responsible for the ground system and routine data processing. Following that, EUMETSAT and NOAA, with the assistance of CNES and NASA, have now assumed responsibility for implementation of the next in this series, Jason-3, with new funding approved in 2010, and a launch planned for 2013/2014. Since Jason-3 uses the last Poseidon bus, ESA is leading a Phase B Study initiated in November 2010 and joint with EUMETSAT, NOAA, CNES and NASA - for the next series of Jason satellites, Jason-CS (Continuity of Service), which will utilize the Cryosat (Cryosphere Satellite) bus.

This also led to the development of two altimeter initiatives to be launched in 2011, the Indian SARAL carrying a CNES AltiKa altimeter and the Chinese HY2A. These will complement the European and U.S. efforts; both will carry a CNES DORIS (Détermination d'Orbite et Radiopositionnement Intégrés par Satellite) tracking system. 


\section{OPERATIONAL NEEDS AND SERVICES}

Monitoring and forecasting of mesoscale ocean signals (with typical scales of 30-300 km and 20-90 days) have applications in fisheries, marine safety, monitoring of oil spills, marine faunal surveys, oil drilling, commercial navigation and military defence. Mesoscale, as well as coastal activities, have a rapid time-space evolution (less than 5 days) which requires a dense and homogeneous temporal and spatial sampling - making necessary the integration of multiple altimeter data streams with derived products being available with short time delay.

\subsection{Operational Oceanography}

The international Global Ocean Data Assimilation Experiment (GODAE) was initiated in 1997 with an objective to establish a global system of observations, communications, modelling and assimilation that will deliver regular, comprehensive information on the state of the oceans. In this framework, operational and research institutions from countries including Australia, France, Italy, Japan, Norway, U.S., and the U.K. have been developing and implementing global ocean data assimilation and ocean forecast systems. As noted in [6], papers presented during the Final GODAE Symposium demonstrate that forecasting of open ocean mesoscale phenomena is feasible, at least in many regions. They also show that the forecasts are useful for some applications (e.g. heat content for tropical cyclones) whilst for other applications the level of forecast skill achieved so far is quite limiting (e.g., the use of surface currents for open-ocean oil spill forecasting) and as a result a high level of expertise is required to make use of them.

Largely as a result of GODAE efforts, operational oceanography has been firmly established, there are operational ocean forecast systems running in a number of countries today. Given their dependence on the availability of adequate observations, concern is noted in [6]: Physical observing systems at basin scale are likely to face the challenge to maintain the current density of Argo and satellite altimeters. Its successor program, GODAE OceanView, will provide a forum where the main operational and research institutions involved in global ocean analysis and forecasting can develop collaborations and international coordination of their activities; as such, it will provide a focal point for helping facilitate further demonstrations of the operational utility of satellite altimetry.

\subsection{Hurricane Forecasting}

Hurricanes are among the most frequently occurring catastrophic events in the warm waters of the global oceans. As noted in [7], Sudden Tropical Cyclone (TC) intensification has been linked with high values of upper ocean heat content contained in mesoscale features, particularly warm eddies. Therefore, resolving, understanding, and monitoring the upper ocean mesoscale field and its vertical thermal structure...may be critical to monitoring the upper ocean heat content for TC intensification studies and forecasts. With this in mind, a number of operational forecast centres are using a relatively recent product as an input to hurricane intensity forecasts. This product, the Tropical Cyclone Heat Potential (TCHP), is an altimeter-derived parameter proportional to the integrated vertical temperature from the sea surface to the depth of the $26^{\circ} \mathrm{C}$ isotherm. It requires merging data from multiple altimeter missions; see Fig. 3 for the dependence of the time it takes to detect a new or moving mesoscale feature as a function of the number of altimeters available.

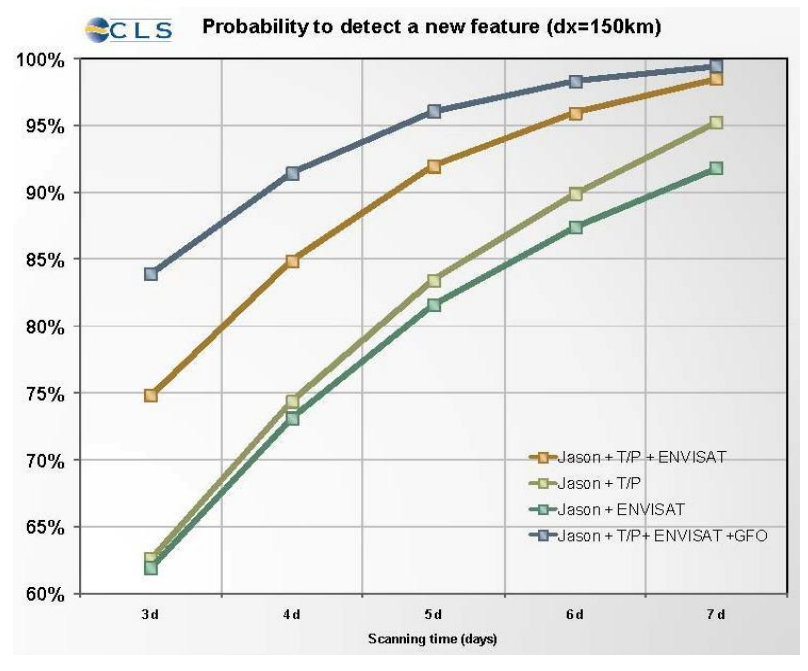

Figure 3. For different combinations of 2, $3 \& 4$ altimeters, the probability of detecting a new or changing mesoscale feature $(\sim 150-\mathrm{km}$ de-correlation length) as a function of days of scanning time. (From [1]).

Again as noted in [7], our current understanding and ability to improve predictions of TC intensification is likely limited by the relative scarcity of observations of the oceans as compared to the atmosphere. Improving the density of those observations - including more advanced and more numerous space-based altimetry capabilities - is needed.

\subsection{Seasonal Forecasting}

Prediction of El Niño-type events is a particularly important issue because of their impact on climate and the associated economic and social activities of affected countries. As noted in [8], several operational centres around the world are issuing routine seasonal forecasts. The skill of those forecasts, previously utilizing in situ observations including those from the TAO/TRITON (Tropical Atmosphere Ocean/Triangle Trans-Ocean Buoy Network) array spanning the Equatorial Pacific, has further improved with the advent of altimeter and Argo data. Therefore, sustainability of the current 
observing system is paramount to continued progress in seasonal forecasting. [8] goes on to note that - while most systems assimilate SST (Sea Surface Temperature), sea level anomalies from altimeter data, and subsurface temperature and salinity data - results have shown that no observing system is redundant, all of them contributing to the improvement of the seasonal forecasts.

Given that the skill of seasonal forecasts is often used to assess the quality of ocean initial conditions, [8] warns that ...this may not always be appropriate since the quality of the coupled model will determine the precision of the assessment - if the major forecast error comes from the coupled model, improvements in the ocean initial conditions would have little impact on forecast skill. Thus, while seasonal forecasting is being done routinely, this is not yet a mature endeavour and significant advances can be expected in the coming decade.

\subsection{Wave Forecasting}

The two parameters measured by altimetry that have established marine meteorological applications are wind speed and significant wave height (SWH). Sea-state forecasts are crucial for many activities related to maritime industries (e.g. fishing, oil drilling, and navigation), and wind speed and SWH measured by altimetry are being used by operational forecast centres in developed countries for assimilation into wave forecast models, validation of those models, developing wave climatologies on seasonal to decadal time scales, and for assessing the role of waves in ocean-atmosphere coupling.

As noted in [9], altimeter wave observations remain a key component of a global wave-observing program. Satellite radar altimeters provide information on significant wave height with global coverage and high accuracy, although spatial and temporal coverage is still marginal. Multiple altimeters are therefore required to provide denser coverage Note that additional observations - dominant wave direction, wave period, one-dimensional energy density spectra, and directional spectra - are also required by operational centres to realize the full benefit from the potential capability of wave forecasting.

Note that even though SWH is the most straight forward and easy-to-use wave product from altimetry and has been available for more than a decade and a half, it is not being used routinely today in most operational forecast centres in developing countries. And if such a straight forward and easy-to-use product as SWH is not being routinely used, the situation must be worse for altimeter-derived sea level products. The developed countries need to be aware of these deficiencies and help their developing country counterparts by providing easy access to and an ability to work with these products.

\section{RESEARCH NEEDS}

The altimetry missions should be designed to provide accurate sea surface topography to determine the general circulation of the ocean and understand its role in the Earth's climate, hydrological and biogeochemical cycles. Very accurate, i.e. within $1 \mathrm{~cm}$ at a basin scale, global, homogeneous and adequately sampled in time and space sea surface topography measurements are required to precisely monitor the ocean and meet the requirements associated with the variety of needs that are described below. How this 1-cm performance translates into requirements for the overall Constellation is described in [1], and how it translates into requirements for two representative missions is described in [10] and [11].

\subsection{Sea Level Rise}

Global sea level rise is the most obvious manifestation of climate change in the oceans, one that directly threatens society along our coastline. Until 1992, the only instruments capable of measuring the trend in global sea level were tide gauges, which have yielded an estimate of about $15 \mathrm{~cm}$ rise over the twentieth century. Since 1992, however, we have a precise 18-year continuous record of global sea level with excellent spatial and temporal resolution collected by satellite altimetry; and during this period the linear rate estimated is $3.1 \pm 0.4 \mathrm{~mm} /$ year, about twice the estimate from tide gauges for the previous century [12].

As discussed in [1], the sea level rise signal - only about 3 millimetres per year on average - must be extracted from records containing large regional variability, and accurate detection of such a small signal is very challenging. It requires millimetre-level control on the potential drifts of the system components (altimeter, geophysical corrections, orbit, reference frame, etc.). The error estimating the trend in sea level will decrease as the time series becomes longer, so this reinforces the need for multi-decadal, continuous altimeter observations. This also requires sufficient overlap for precise inter-calibration to resolve the measurement bias between missions.

It is important to maintain the Jason series and the complementary altimeters for the foreseeable future to extend the time series documenting global sea level rise. One key step in creating this record is the need to compare and combine altimeter observations from the various missions in the most consistent way possible. This requires a database specifically designed for experimentation, such as the Radar Altimeter Database System (RADS). First developed at the Delft University of Technology in the late 1990s and maintained by 
NOAA for the past seven years, RADS $^{2}$ provides public access to all of the altimeter measurements made since 1985 with the most consistent, up-to-date geophysical corrections, as well as any user provided corrections. Users of the database can tailor the computation of sea level estimates based on a preference for certain correction models, or applicability to particular regions, thus allowing the development of sea-level climate data records to be a community activity.

In order to advance our understanding of global sea level rise, it is also important to maintain additional systems such as the GRACE (Gravity Recovery And Climate Experiment) satellite - launched in 2002 - to estimate changes in mass due to the addition of water from melting glaciers and ice sheets, as well as the Argo array - which achieved global coverage in 2007 - to estimate changes in volume due to the warming of the oceans.

\subsection{Ocean State Estimation}

Regarding ocean climate analyses and state estimation, discussed in [13] and [14], estimation of the decadal and longer-term variability remains a challenge due to the lack of observations at these time scales of the oceans and its forcing fields, as well as an understanding of the associated errors. Therefore, the most pressing need for the ocean observing system, from this climate perspective, includes - at the very minimum - the maintenance of the current global systems for the foreseeable future.

Moreover, many state estimation products have resolutions too coarse to represent mesoscale eddies. As these eddies affect the climate through their interaction with the larger scales, it is imperative that ocean state estimation efforts move toward eddypermitting resolutions to more fully utilize the existing observations that capture eddy variability [15]. It is therefore important that, in addition to the Jason series, the complementary altimeters be maintained as well as the Jason series, at least until such time as the wideswath altimeter (discussed below) has been developed and demonstrated.

\subsection{Decadal Prediction}

While several operational centres around the world are issuing routine seasonal forecasts, decadal forecasting is still in its infancy [8]. This situation is best described in [15]:

Given imperfect observations and systematic errors in models, the best method of initialization has not yet been established and it is not known what effect initialization has on climate predictions. The brevity of most instrumental records furthermore means that even the basic characteristics and mechanisms of decadal

\footnotetext{
${ }^{2}$ http://rads.tudelft.nl/rads/rads.shtml
}

variations in climate are relatively poorly documented and understood... Demands will therefore be made on observations, particularly ocean observations, not only to describe the state of the climate system and improve knowledge of the mechanisms that give rise to decadal fluctuations in climate, but also to provide the optimal observations for decadal climate predictions and their verification.

Thus, it is also important to maintain the Jason series and complementary altimeters for the foreseeable future since ocean observations will be at the heart of climate prediction systems.

\subsection{Coastal Applications}

Satellite altimetry over the open ocean is reasonably well understood and data are routinely utilized for a variety of ocean applications. On the other hand, many operational needs occur close to the coast, and fully resolving the rapid time-space scale processes especially those less than $20 \mathrm{~km}$ from the coast - are dependent on dedicated processing with adequate corrections (e.g., tides and water vapour), as well as effective removal of land contamination. Additionally, as for mesoscale studies, multi-mission data merging is required to improve the spatial and temporal resolution. However, to the extent that these can be adequately addressed, altimetry has the potential to contribute current and wave observations for use in beach erosion and sediment transport studies, coastal defence design and operation, and monitoring of storm surges.

As discussed in [16], research into these coastal applications has now produced the first such customprocessed coastal altimetry data sets. These are now available to the community at large and many more will become so in the near future. Indeed, 18 years of coastal altimetry from various past and present altimeters are waiting to be processed and offer the prospect of describing the status of the world's coastal waters, including many stretches where satellite altimetry may provide the only measurement coverage.

\subsection{Sub-Mesoscale Applications}

Satellite altimetry has substantially advanced our understanding of the oceans by providing unprecedented observations of the surface topography at scales larger than $200 \mathrm{~km}$, for example, contributing to an improved understanding of global ocean circulation and global sea level rise.

However, as discussed in [17] and [18], coarse crosstrack sampling and measurement precision associated with present techniques have prevented resolving scales smaller than $\sim 100 \mathrm{~km}$. While mesoscale eddies are responsible for transporting properties horizontally in the upper ocean, variability at the sub-mesoscale e.g. fronts and filaments - accounts for about half of the 
total vertical transport. And to estimate the associated vertical velocities, a much finer spatial sampling is required to resolve the convergences and divergences in the horizontal velocity field that drive them. Until that is done, an understanding of vertical transfer processes for heat, nutrients, and dissolved $\mathrm{CO}_{2}-$ important for understanding the role of the oceans in climate - will be lacking.

\section{NEW TECHNOLOGY}

Technology with an order of magnitude improvement in spatial resolution is available today. The first and nearest-term technology - the adoption of delayDoppler processing of the echo returns - will represent a dramatic improvement to nadir-pointing, along-track altimetry. This will result in either a much higher along-track resolution, an improved signal-to-noise ratio, or some combination of both. Another benefit is reduced sensitivity of the measurements to the sea state. (Note that across-track resolution is limited by the antenna beam width to $\sim 10 \mathrm{~km}$.) The first delay-Doppler altimeter (DDA, also called SIRAL, a SAR interferometric radar altimeter) in space, launched on CryoSat-2 in April 2010; ESA will also use a DDA on the Sentinel-3 series; these will feature a $250-\mathrm{m}$ and 300-m along-track resolutions, respectively. This technique will make a significant contribution to both sub-mesoscale and coastal applications, as well as riverlevel monitoring. See [17] and [19] for additional information.

As discussed in [18], the next available technology - the wide-swath altimeter - will extend the observational capability of altimetry to the cross-track direction. Interferometry synthetic aperture radar processing of the returned pulses can yield, with averaging over $\sim 1 \mathrm{~km}^{2}$, a height precision of less than $2 \mathrm{~cm}$. This technology will be employed on the Surface Water Ocean Topography (SWOT) mission, proposed for launch late this decade.

SWOT is being designed to achieve this performance over a $\sim 130-\mathrm{km}$ swath, and it is being justified on the basis of its contribution to both ocean dynamics and land hydrology. It represents a fundamental breakthrough in observational capability, providing an orderof-magnitude finer resolution than what can presently be achieved by merging data from conventional altimeters. While it will represent a refinement in our capability to observe the mesoscale, the twodimensional map of the surface topography of the ocean from SWOT will represent a fundamental break through in our capability to observe the here-to-fore unresolved sub-mesoscale and coastal domains, by producing highresolution maps of two-dimensional local slopes, essential for deriving ocean currents and river discharge.

An alternative to address sub-mesoscale applications is to place an altimetry package on a dozen or two dedicated micro satellites or as piggyback payloads on flights of opportunity such as the Iridium Next initiative. Orbits for the satellites would be optimized to maximize temporal and spatial coverage, as well as revisit time. The measurements from such a constellation would need to be collected concurrently with a high-accuracy reference mission. Preliminary performance simulations of such a constellation show promising results.

An emerging technology is Global Navigational Satellite System (GNSS) reflectrometry. This involves the analysis of travel time of signals emitted by GNSS satellites (one example being GPS), reflected at the ocean surface and received by low-orbiting satellites. As stated in [19]... a number of groups are currently investigating the accuracy of such a measurement. First results look promising, but the technique is far from being well established.

\section{RECOMMENDATIONS}

The following recommendations reflect consensus views with regard to the Symposium on 15 Years of Progress in Radar Altimetry [2] held in Venice in March 2006, the Ocean Surface Topography Constellation Strategic Workshop [3] held in Assmannshausen in January 2008, and The Next 15 Years of Satellite Altimetry: Ocean Surface Topography Constellation User Requirements Document [1] that was completed on 30 September 2009.

- Maintain continuity of high-accuracy Jason altimetry to serve as the reference mission for the foreseeable future - with adequate overlap between successive missions.

- Maintain continuity with altimeters on at least two, preferably three, complementary high-inclination satellites for the foreseeable future - with orbital characteristics selected, to the extent possible, to optimize coverage of the ocean surface topography.

- Extend the capability of altimetry to denser observational coverage through wide-swath altimetry - maintaining the reference and complementary missions until such time as the adequacy of this technique has been demonstrated and implemented on a continuing basis.

- Maintain an open data policy including near-real time data (including both level 1 and level 2) for operational purposes - promoting timely access to data to all for the public good, typically within three hours of collection for operational use and with a reasonable delay for research.

- Maintain a continuing partnership with the scientific community - including competitively selected science teams as an integral element of the missions to ensure data quality, especially for sea level as an Essential Climate Variable. 
- Maintain broad collaboration between engineering and science, research and operations, and international partners - facilitating the transition of demonstrated capabilities from research agencies into corresponding capabilities within the operational agencies, the optimization of coverage and performance of the Constellation, and the sharing of experience in the utilization of data.

In conclusion, there is much work to do to realize these recommendations in the coming 15 years. However, barring unforeseen accidents, the prospects for the international community of users to have a continuing source of data from both a reference and complementary altimeter missions - based on Fig. 4 - look guardedly optimistic for the coming decade.

GLOBAL ALTIMETER MISSIONS

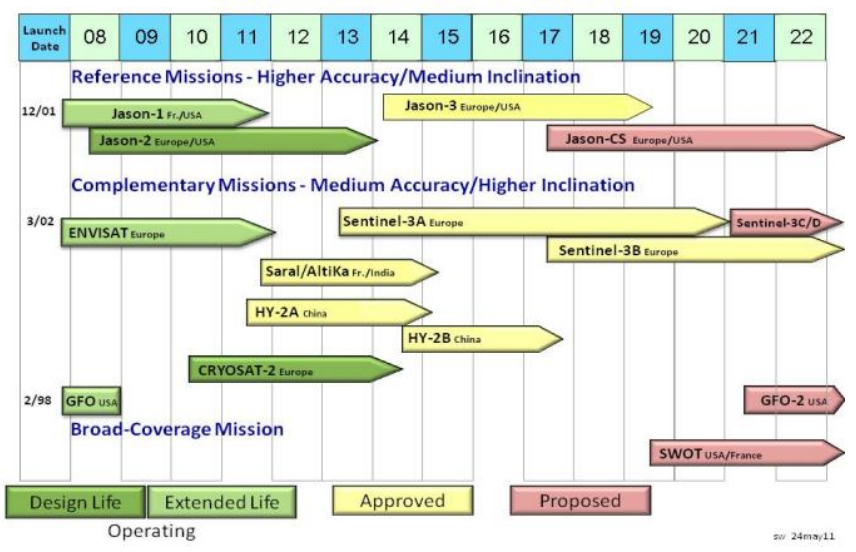

Figure 4. Schedule for and status of the various altimeter missions comprising the Ocean Surface Topography Constellation.

\section{REFERENCES}

1. Escudier, P. \& Fellous, J. (2009). The Next 15 Years of Satellite Altimetry: Ocean Surface Topography Constellation User Requirements Document. CLS.DOS/NT/09.092, 47 pp.

2. Benveniste, J. \& Ménard, Y., (eds.) (2006) Proceedings of the 15 Years of Progress in Radar Altimetry Symposium, Venice, Italy, 13-18 March 2006, ESA Special Publication SP-614.

3. Wilson, S. \& F. Parisot (2008). Report of CEOS Ocean Surface Topography Constellation Strategic Workshop, Assmannshausen, 29-31 January 2008, EUMETSAT Report E.02, v1, 4 pp.

4. Koblinsky, C. Gaspar, P. \& Lagerloef, G. (eds) (1992). The Future of Spaceborne Altimetry - Oceans and Climate Change: A Long-Term Strategy. Joint Oceanographic Institutions, Inc., $85 \mathrm{pp}$.

5. Pascual, A., Faugère, Y., Larnicol, G. \& LeTraon, P-T. (2006). Improved Description of the Ocean Mesoscale Variability by Combining Four Satellite Altimeters, Geophysical Research Letters 33(2)13-16, doi:10.1029/2005GL024633
6. Le Traon, P., Bell, M., Dombrowsky, E., Schiller, A. and Wilmer Becker, K., (2010). "GODAE OceanView: From an Experiment Towards a Long-Term International Ocean Analysis and Forecasting Program" in these proceedings (Vol. 2), doi:10.5270/OceanObs09.cwp.57.

7. Goni, G. \& Co-Authors (2010). "The Ocean Observing System for Tropical Cyclone Intensification Forecasts and Studies" in these proceedings (Vol. 2), doi:10.5270/OceanObs09.cwp.36.

8. Balmaseda, M. \& Co-Authors (2010). "Initialization for Seasonal and Decadal Forecasts" in these proceedings (Vol. 2), doi:10.5270/OceanObs09.cwp.02,

9. Swail, V. \& Co-Authors (2010). "Wave Measurements, Needs and Developments for the Next Decade" in these proceedings (Vol. 2), doi:10.5270/OceanObs09.cwp.87.

10. Bonekamp, H., Miller, L. \& Leetmaa, A. (eds) (2007). Jason-3 Applications Working Group Final Report, EUMETSAT Report EUM/MET/REP/07/0076, 45 pp.

11. Drinkwater, M \& Rebhan, H. (2007) Sentinel-3: Mission Requirements Document, ESA Report EOPSMO/1151/MD-md, 60pp.

12. Nerem, R. \& Co-Authors (2010). "Observations of Sea Level Change: What Have We Learned and What Are the Remaining Challenges?" in these proceedings (Vol. 2), doi:10.5270/OceanObs09.cwp.65.

13. Heimbach, P. \& Co-Authors (2010). "Observational Requirements for Global-Scale Ocean Climate Analysis: Lessons from Ocean State Estimation" in these proceedings (Vol. 2), doi:10.5270/OceanObs09.cwp.42.

14. Lee, T. \& Co-Authors (2010). "Ocean State Estimation for Climate Research" in these proceedings (Vol. 2), doi:10.5270/OceanObs09.cwp.55.

15. Hurrell, J. \& Co-Authors (2010). "Decadal Climate Prediction: Opportunities and Challenges" in these proceedings (Vol. 2), doi:10.5270/OceanObs09.cwp.45.

16. Cipollini, P. \& Co-Authors (2010). "The Role of Altimetry in Coastal Observing Systems" in these proceedings (Vol. 2), doi:10.5270/OceanObs09.cwp.16.

17. Scott, R. \& Co-Authors (2010). "Satellite Altimetry and Key Observations: What We've Learned, and What's Possible with New Technologies" in these proceedings (Vol. 2), doi:10.5270/OceanObs09.cwp.76.

18. Fu, L. \& Co-Authors (2010). "The Surface Water and Ocean Topography (SWOT) Mission" in these proceedings (Vol. 2), doi:10.5270/OceanObs09.cwp.33.

19. Shum, C. \& Co-Authors (2010). "Geodetic Observations of the Ocean Surface Topography, Geoid, Currents, and Changes in Ocean Mass and Volume" in these proceedings (Vol. 2), doi:10.5270/OceanObs09.cwp.80. 